\title{
Adding diffuse reflectance infrared Fourier transform spectroscopy capability to extended $x$-ray-absorption fine structure in a new cell to study solid catalysts in combination with a modulation approach
}

\author{
Gian Luca Chiarello, ${ }^{1}$ Maarten Nachtegaal, ${ }^{2}$ Valentina Marchionni, ${ }^{2}$ Luca Quaroni, ${ }^{2}$ \\ and Davide Ferri ${ }^{2, a)}$ \\ ${ }^{1}$ Dipartimento di Chimica, Università degli Studi di Milano, Via C. Golgi 19, I-20133 Milano, Italy and Empa, \\ Swiss Federal Laboratories for Materials Science and Technology, Lab. for Solid State Chemistry and \\ Catalysis, Ueberlandstrasse 129, CH-8600 Dübendorf, Switzerland \\ ${ }^{2}$ Paul Scherrer Institut, CH-5232 Villigen PSI, Switzerland
}

(Received 22 May 2014; accepted 8 July 2014; published online 28 July 2014)

\begin{abstract}
We describe a novel cell used to combine in situ transmission X-ray absorption spectroscopy (XAS) with diffuse reflectance infrared Fourier transform spectroscopy (DRIFTS) in a single experiment. The novelty of the cell design compared to current examples is that both radiations are passed through an X-ray and IR transparent window in direct contact with the sample. This innovative geometry also offers a wide surface for IR collection. In order to avoid interference from the crystalline IR transparent materials (e.g., $\mathrm{CaF}_{2}, \mathrm{MgF}_{2}$, diamond) a $500 \mu \mathrm{m}$ carbon filled hole is laser drilled in the center of a $\mathrm{CaF}_{2}$ window. The cell is designed to represent a plug flow reactor, has reduced dead volume in order to allow for fast exchange of gases and is therefore suitable for experiments under fast transients, e.g., according to the concentration modulation approach. High quality time-resolved XAS and DRIFTS data of a $2 \mathrm{wt} \% \mathrm{Pt} / \mathrm{Al}_{2} \mathrm{O}_{3}$ catalyst are obtained in concentration modulation experiments where $\mathrm{CO}\left(\right.$ or $\left.\mathrm{H}_{2}\right)$ pulses are alternated to $\mathrm{O}_{2}$ pulses at $150^{\circ} \mathrm{C}$. We show that additional information can be obtained on the Pt redox dynamic under working conditions thanks to the improved sensitivity given by the modulation approach followed by Phase Sensitive Detection (PSD) analysis. It is anticipated that the design of the novel cell is likely suitable for a number of other in situ spectroscopic and diffraction methods. (C) 2014 AIP Publishing LLC. [http://dx.doi.org/10.1063/1.4890668]
\end{abstract}

\section{INTRODUCTION}

The analysis of the working structure of a solid catalyst is crucial to catalyst and process development and in a broader view to material science. This information can be obtained by exploiting the pletora of spectroscopic and diffraction methods available nowadays at lab scale and at synchrotron facilities. Because each method requires a specific sample geometry and environment in order to couple the probing radiation, combination of two or more spectroscopic methods in a single experiment and therefore in a single reactor cell is desirable to guarantee identical reaction conditions. ${ }^{1,2}$ This allows circumventing the issue of measurement reproducibility in the different reactor cells that have been designed for each single method $^{3,4}$ and serves also as an external control for possible radiation damage. ${ }^{5}$

X-ray absorption spectroscopy (XAS) probes the short range structure of a material and is extremely useful in the investigation of catalytic active sites of solid catalysts under relevant operation conditions. ${ }^{6,7}$ Infrared spectroscopy interrogates the vibrational states of the solid catalyst and of adsorbates thus providing molecular level information on the state of the material under reaction conditions. ${ }^{8-10}$ The diffuse reflectance infrared Fourier transform (DRIFTS) mode is highly adequate to study powder materials under controlled reaction

a) Author to whom correspondence should be addressed. Electronic mail: davide.ferri@psi.ch. Phone: +4156310 2781. conditions without the need to shape them into wafers. ${ }^{11,12}$ The combination of the XAS and vibrational spectroscopy probing different length scales but providing complementary information at both the atomic and the molecular levels during reaction is powerful and can be achieved in a single spectroscopic reactor cell provided that specific requirements are met. ${ }^{13,14}$

To present, only few examples of this powerful combination exist. Pioneering work was made by Newton at beamline ID24 of the European Synchrotron Radiation Facility (ESRF, Grenoble, France). ${ }^{15}$ The design is after that reported by Cavers et al. ${ }^{16}$ and the schematic drawing is reported in Ref. 17. It is based on the DRIFTS cell originally commercialized by Spectra Tech, where the IR radiation is coupled into the cell via a hemispherical $\mathrm{ZnSe}$ dome (HP/HT). The original dome was replaced by a top flat window in order to reduce the cell volume. In the ESRF design, the $\mathrm{ZnSe}$ dome is replaced by the $\mathrm{HP} / \mathrm{HV}$ version consisting of two $\mathrm{CaF}_{2}$ windows (Figure 1(a)). Coupling of the X-rays was achieved by modification of the material and the design of the sample cup. The infrared radiation is brought to the sample externally to an IR spectrometer and using the original SpectraTech set of mirrors. The X-rays are typically focused $\sim 100 \mu \mathrm{m}$ below the sample surface, thus approximately within the penetration depth of the IR radiation into the sample $(\sim 200 \mu \mathrm{m}) .{ }^{18}$ The $\mathrm{X}$-rays penetrate to and exit from the sample through vitreous carbon windows mounted on the original HP/HV dome. The cell can be used for both energy dispersive and quick EXAFS 

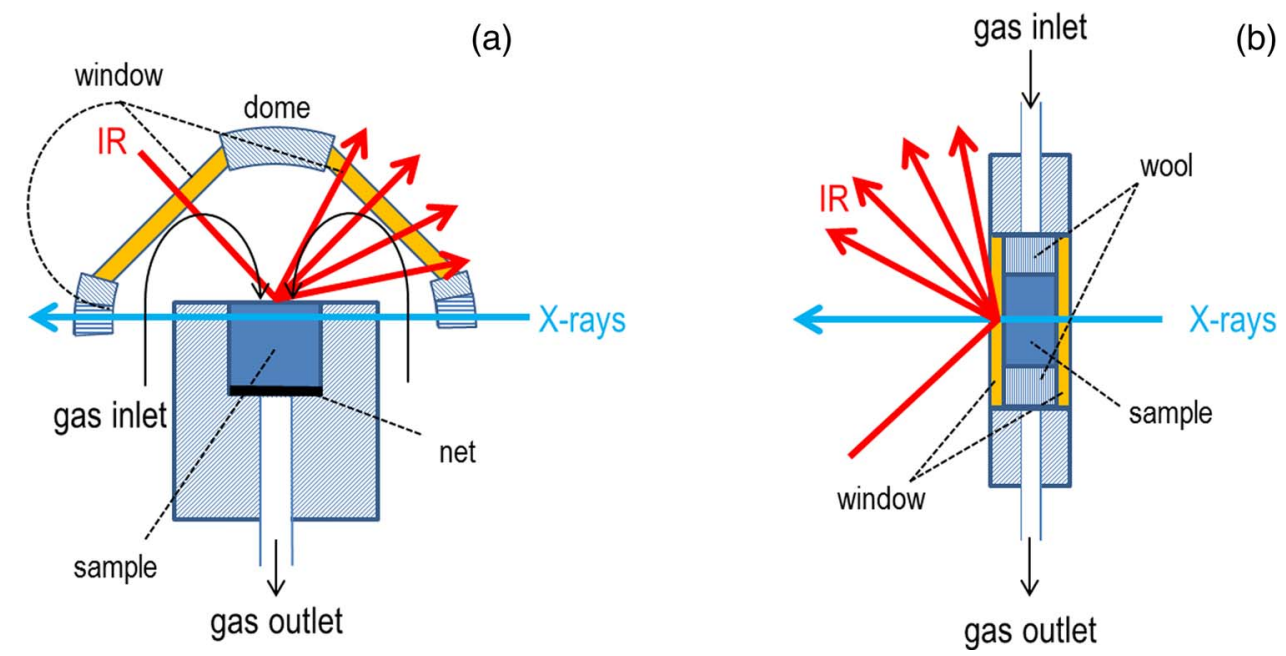

FIG. 1. Cartoons (a) of previously reported cells for combined XAS-DRIFTS measurements based on the dome geometry and (b) of the novel XAS-DRIFTS cell of this work.

measurements and is also powerful for combined high energy X-ray diffraction/DRIFTS studies. ${ }^{19}$

The original Spectra Tech construction was critically considered by Meunier et al. ${ }^{20}$ and accordingly modified for optimal operation in terms of a plug-flow reactor to avoid bypass of the sample. ${ }^{21}$

The second known cell for combined XAS-IR experiments has been produced at Brookhaven National Laboratory. ${ }^{22}$ The infrared radiation is brought to the sample using a Harrick daVinci arm mounted in the sample compartment of the IR spectrometer. The cell is a high temperature and high pressure Harrick cell where the dome and the sample cup have been adapted to allow coupling of the X-rays in a similar geometry to that of the SpectraTech cell (Figure 1(a)). A major difference between the Spectra Tech and the Harrick cells is that in the former the thermocouple is inserted on the top of the sample bed thus enabling controlling the sample temperature. ${ }^{23}$

Recently, the Harrick cell has been differently modified at Argonne National Laboratory to allow for the combination of DRIFTS with X-ray pair distribution function (PDF) analysis. ${ }^{24}$ The cell and Praying Mantis optic are mounted in an external cabinet attached to the side of the FTIR spectrometer. Coupling of the X-rays onto the sample is achieved via a slot cut on the incident side of the dome structure in a similar manner to that shown in Figure 1(a). In order to ensure collection of scattered X-rays at the useful angles an X-ray window is mounted on the dome additionally to the two IR transparent windows. Finally, a third and conceptually different geometry has been proposed in Marcelli et al. ${ }^{25}$ but no data have been reported so far.

In the aforementioned cells the combination of the two spectroscopic methods in a single experiment has been realized by adaptation of a commercial infrared cell (the SpectraTech or the Harrick cells) for the use with X-rays. The advantage is that the cell makes use of the available infrared optics and only minor changes have to be made to the environment around the sample thanks to the high penetration of X-rays. The major disadvantages are the long X-ray travel path, due to the size of the sample cup, allowing the investigation of diluted samples only (or requiring high energy X-rays with sufficient penetration depth to travel through the $3-5 \mathrm{~mm}$ sample cup) and the implicit large dead volume that limits time resolution (Figure 1(a)). This is $\sim 14 \mathrm{~cm}^{-3}$ in the Harrick cell and $\sim 3 \mathrm{~cm}^{-3}$ in the modified Spectra Tech cell of Ref. 15.

Our aim was to manufacture and test a novel spectroscopic reactor cell for combination of time-resolved XAS and IR spectroscopy in the diffuse reflectance mode. The basic idea is to place the catalyst bed perpendicular to both the $\mathrm{X}$-ray and IR beams, thus shining both radiations through the same optical window (Figure 1(b) and Figure 2(a)). The major issue in this new cell design is to find the specific optical window transparent to both X-ray and IR. Coupling of X-rays in a reactor cell is more easily achieved compared to IR radiation because of their stronger penetration depth and because of the range of window materials that can be used. Typical $\mathrm{X}$-ray transparent windows are made of light elements, such as Be, graphite, quartz and mica, which are not IR transparent. For vibrational spectroscopy, specific windows are required that are often not suitable for use under reaction conditions of chemicals/gases and high temperature. $\mathrm{CaF}_{2}$ or $\mathrm{MgF}_{2}$ are good IR window in consideration of their chemical and thermal stability but their crystallinity can interfere with the XAS measurements.

Contrary to commercial DRIFTS cells, the cell is also conceived to bear a reduced dead volume ideally suited for transient response methods to study powder materials, e.g., catalysts and sensors. One such method is the modulated excitation (ME) approach, ${ }^{26}$ where the response of spectroscopically weak signals can be enhanced upon repeated and continuous perturbation of the sample environment, e.g., gas phase concentration changes, while the spectroscopic acquisition is carried out. The method was developed for IR spectroscopy and first used with DRIFTS by Cavers et al. ${ }^{16}$ and its use has been extended to UV-vis spectroscopy, ${ }^{27} \mathrm{XAS},{ }^{28-32}$ and $\mathrm{X}$-ray diffraction (XRD). ${ }^{33-37}$ The cell is conveniently designed to allow also coupling of high energy $\mathrm{XRD}^{38}$ (thus 
(a)

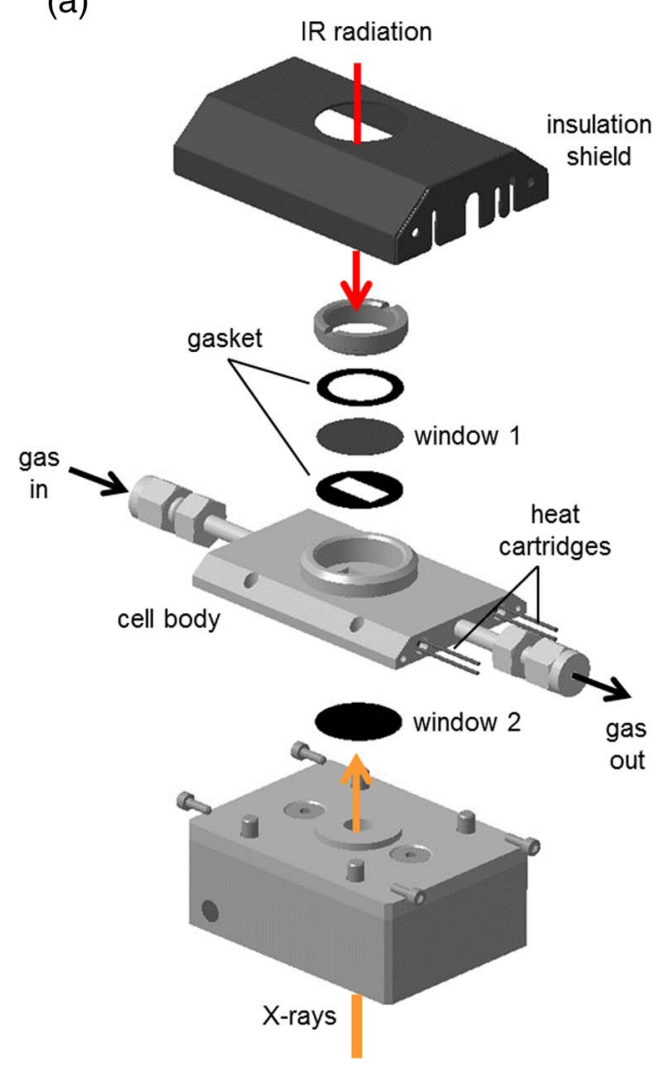

(b)

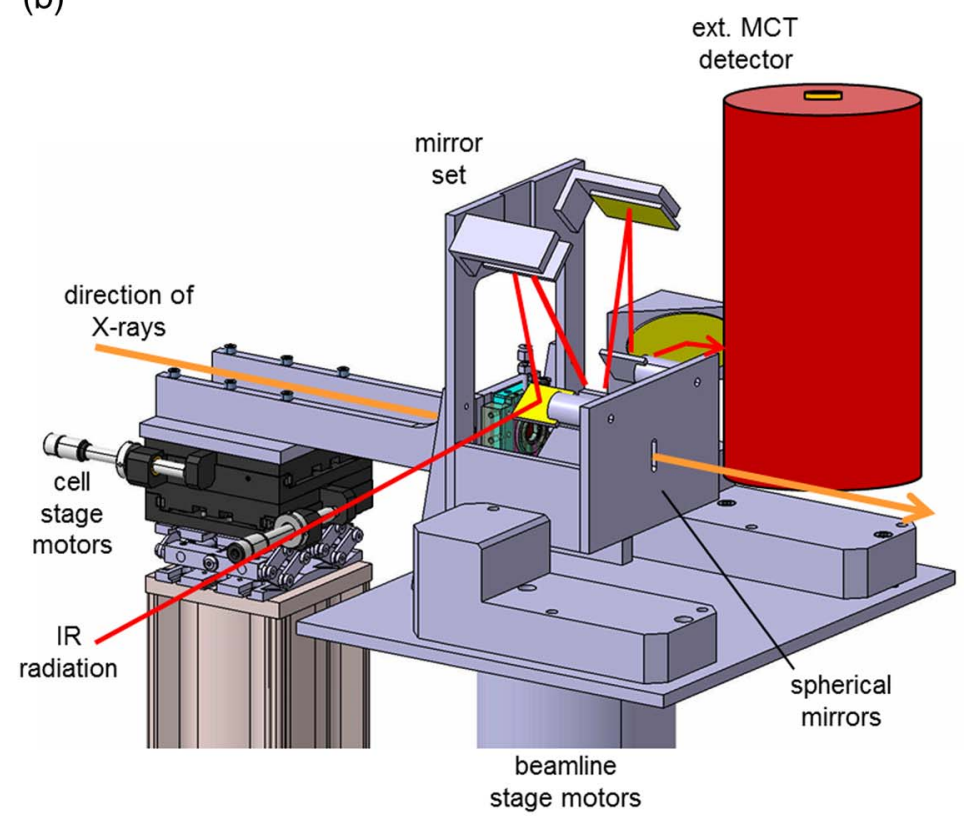

FIG. 2. (a) Exploded view of the proposed cell for combined XAS and DRIFTS measurements. (b) Cell arrangement within the DRIFTS mirror set external to the IR spectrometer and in the path of the X-rays. The mirror set is mounted on the beamline motors. The cell is mounted on a set of motors independent from the mirror set.

likely also pair distribution function, PDF), Uv-vis and Raman spectroscopies provided that the correct window material or combination of windows is selected. Therefore, a universal cell is presented here that allows catalyst investigation using a number of techniques with a single sample geometry thus enabling exact reproducibility of experiments with spectroscopic methods, which is central to the determination of the nature of active sites of solid catalysts.

\section{EXPERIMENTAL}

\section{A. Cell design}

The cell (Figure 2(a)) consists of a $2 \mathrm{~mm}$ thick corrosion resistant stainless steel block (sample holder) in which a rectangular $5 \mathrm{~mm} \times 10 \mathrm{~mm}$ aperture is cut in the middle that serves as the emplacement of the sample. Typically, the sample (100-200 $\mu \mathrm{m}$ sieve fraction) is closed between two optical windows (windows 1 and 2 in Figure 2(a); $14.8 \mathrm{~mm}$ diameter) and firmly placed between two quartz wool plugs. Two heat cartridges (each delivering $45 \mathrm{~W}$ ) are inserted along the stainless steel block on the sides of the sample position to guarantee homogeneous temperature distribution. The cell was tested up to $500{ }^{\circ} \mathrm{C}$. Two stainless steel tubes with $1 / 16$ in. connector are soldered on the two short sides of the block, which allows for gas admittance through the catalyst bed. A K-type thermocouple $(0.5 \mathrm{~mm})$ is inserted directly into the sample through the $1 / 16$ in. gas inlet tube, thus enabling easier monitoring of the sample temperature. ${ }^{23}$ For X-ray absorption experiments only, a graphite window (300 $\mu \mathrm{m}$ thick) is placed on each side of the sample aperture (window 1 and window 2 in Figure 2(a)). For combined IR-XAS experiments a suitable IR transparent window (window 1) is placed between two graphite gaskets. On both sides, the sample is in close contact with the window. The back side of the cell (window 2) is tightened by an additional stainless steel block containing a thermal insulation layer on top (i.e., in contact with the first heating block), a water-cooled circuit at the bottom and a round aperture in the middle allowing the X-ray to pass. The top of the cell is covered by quartz wool protected by an insulation shield thus preventing excessive heat loss.

The cell can be mounted on a homemade holder to fit into the mirror setting of the commercial Praying Mantis unit (Harrick) to be used in a commercial IR spectrometer. Adaptation to other diffuse reflectance units is possible. For synchronous XAS-IR measurements, in the experimental hutch the cell is mounted on a manual $\mathrm{x}, \mathrm{y}, \mathrm{z}$ stage that is completely independent from the DRIFTS mirror unit placed on the motorized stage of the beamline together with the liquid $\mathrm{N}_{2}$ cooled $\mathrm{HgCdTe}$ detector (Figure 2(b)). This is realized in order to avoid possible heating of the mirrors by contact with the hot cell and to provide more flexibility. Given the geometry of the cell, the DRIFTS mirror unit is not mounted in the conventional geometry but is rotated by $90^{\circ}$ as shown in Figure 2(b). $\mathrm{X}$-rays have a free pass through the gap between the two diffuse reflectance spherical mirrors. The infrared radiation 
is coupled outside the IR spectrometer (Vertex 70V, Bruker) from the front side onto the first flat mirror of the DRIFTS mirror unit (Figure 2(b)). Because IR transparent windows are crystalline, a hole $(0.5 \mathrm{~mm})$ was laser drilled in the middle of the $\mathrm{CaF}_{2}$ window and filled with a high temperature carbon based glue $\left(1100^{\circ} \mathrm{C}\right.$, Fermit GmbH, Germany). This geometry allows passing the $\mathrm{X}$-rays through the hole and to simultaneously record IR spectra without interference of the IR material.

\section{B. Modulated excitation spectroscopy}

In the modulated excitation (ME) approach the environment around the sample is periodically perturbed, e.g., through repeated changes of gas concentration, while the spectroscopic acquisition is carried out. The set of timeresolved data can be processed into a new set of phaseresolved data using phase sensitive detection (PSD) that is based on the following equation: ${ }^{26}$

$$
\mathrm{I}\left(\varphi^{\mathrm{PSD}}\right)=\frac{2}{\mathrm{~T}} \int_{0}^{\mathrm{T}} \mathrm{I}(\mathrm{t}) \sin \left(k \omega \mathrm{t}+\varphi^{\mathrm{PSD}}\right) \mathrm{dt},
$$

where $\omega(2 \pi / T)$ is the stimulation frequency, $\mathrm{k}$ is the demodulation index $(\mathrm{k}=1$ is the fundamental harmonics), and $\mathrm{I}(\mathrm{t})$ is the intensity recorded as a function of time and energy. PSD allows the isolation of spectroscopic signals, typically weak, responding to the external stimulation from the static signals, typically overwhelming. Beside revealing the kinetics between two species transforming one into the other one, the method has shown great capability to enhance the sensitivity of XAS and to isolate intermediate species. ${ }^{28,31}$

In order to test the performance of our new XAS-IR cell for fast transient study, ME experiments were carried out over a $2 \mathrm{wt} . \% \mathrm{Pt} / \gamma-\mathrm{Al}_{2} \mathrm{O}_{3}$ catalyst kindly provided by Umicore (surface area: $140 \mathrm{~m}^{2} / \mathrm{g}$; Pt dispersion: $11.5 \%$ ). ${ }^{39}$ Unless otherwise mentioned, the experiment consisted of 30 alternate and equally long pulses (33 s) of $5 \mathrm{vol} . \% \mathrm{CO} / \mathrm{He}$ (or $5 \mathrm{vol} . \%$ $\mathrm{H}_{2} / \mathrm{He}$ ) and 5 vol. $\% \mathrm{O}_{2} / \mathrm{He}$ (if not otherwise mentioned) at $150{ }^{\circ} \mathrm{C}$ after in situ reduction at $300^{\circ} \mathrm{C}$ in $5 \mathrm{vol} . \% \mathrm{H}_{2} / \mathrm{He}$ at $100 \mathrm{ml} / \mathrm{min}$ flow rate. These experiments provide information on (i) the redox dynamics of $\mathrm{Pt}$ when exposed to alternate reducing $\left(\mathrm{H}_{2}\right.$ or $\left.\mathrm{CO}\right)$ or oxidizing $\left(\mathrm{O}_{2}\right)$ atmosphere (obtained by $\mathrm{XAS}$ ) and (ii) the molecular species involved in $\mathrm{CO}$ oxidation (obtained by DRIFTS).

The ME experiments have been carried out in a Bruker Vertex70V FT-IR spectrometer equipped with a liquid nitrogen cooled HgCdTe detector and a Praying Mantis unit (Harrick) in order to test the performance of the new XAS-IR cell in comparison with the commercial HVC-DRP2 Harrick DRIFTS cell. The conventional dome of the commercial DRIFTS cell was replaced by a $2 \mathrm{~mm}$ thick flat $\mathrm{CaF}_{2}$ window ( $d=25 \mathrm{~mm}$, Crystran Ltd.) positioned $1 \mathrm{~mm}$ from the top of the sample. The spectrometer was interfaced to a similar gas manifold to that used for the combined XAS-IR measurements. All DRIFTS measurements were performed at $4 \mathrm{~cm}^{-1}$ resolution by co-adding 11 interferograms at $80 \mathrm{kHz}$ scanner velocity.
Synchronous in situ XAS/DRIFTS experiments were performed at beamline SuperXAS of the Swiss Light Source (SLS) at PSI (Villigen, Switzerland) ${ }^{40}$ using the quick scanning monochromator. The polychromatic light of the ring was collimated using a Rh coated mirror before the monochromator and focused using a Rh coated torroidal mirror after the monchromator to a spot size of $100 \mu \mathrm{m} \times 100 \mu \mathrm{m}$. Samples were measured in transmission mode using He-filled ion chambers. Full $\mathrm{Pt}_{3}$-edge quickEXAFS spectra were recorded in transmission mode with a $1 \mathrm{~s}$ time resolution. The synchronous DRIFTS spectra were acquired with a Bruker Vertex $70 \mathrm{~V}$ spectrometer by co-adding 12 interferograms at 10 $\mathrm{kHz}$ scanner velocity and at $4 \mathrm{~cm}^{-1}$ resolution.

Pulse sequences and IR acquisition were set using the rapid scan option of the OPUS software (Bruker). The quickEXAFS acquisition was started simultaneously to the IR acquisition. The electric signal $(0-5 \mathrm{~V})$ of one of the two solenoid switch valves, which are triggered by OPUS, was recorded together with the quickEXAFS signals, allowing the synchronization of both the IR and XAS time-resolved data sets. For the combined XAS-IR experiments, the IR spectrometer is mounted on a moving stage that can be lifted so that the IR radiation matches the height of the X-rays at the sample position.

In all measurements, a quadrupole mass spectrometer (Omnistar, Pfeiffer) was used to monitor online the gas phase species.

\section{RESULTS AND DISCUSSION}

\section{A. Characterization of time resolution using DRIFTS}

Commercial DRIFTS cells possess an intrinsically large dead volume that makes them not suitable for transient response experiments, i.e., when the atmosphere around the sample cannot be changed quickly (Figure 1(a)). This issue was tackled, for example, by Schubert et al. ${ }^{41} \mathrm{Dal}$ Santo et al. ${ }^{42}$ Urakawa et al.,${ }^{43}$ and Meunier et al. ${ }^{20}$ The present cell was designed for combination of DRIFTS and XAS techniques and additionally to allow for transient studies using modulation approaches. The plug-flow reactor type design allows for a better and faster exchange of the gas phase. Figure 3 shows the comparison between the signal of the $\mathrm{He}(\mathrm{m} / \mathrm{z}=4)$ marker gas recorded after the cell (operated at $150^{\circ} \mathrm{C}$ ) using the online mass spectrometer during an identical modulation experiment consisting of repeated and alternated pulses of $2.5 \mathrm{vol} . \% \mathrm{CO} / 2.5 \mathrm{vol} \% \mathrm{He} / \mathrm{Ar}(33 \mathrm{~s})$ and $2.5 \mathrm{vol} \% \mathrm{O}_{2} / \mathrm{Ar}(33 \mathrm{~s})$ in the new (Figure 3(a)) and the commercial (Figure 3(b)) cells at a flow rate of $100 \mathrm{ml} / \mathrm{min}$. Except for the cell geometry, the gas feeding system from the switch valves to the cell and from the cell to the mass spectrometer was identical. In the novel cell, the gas is completely exchanged within $\sim 5 \mathrm{~s}$, which is likely provided by the dead volume of the tubing to and from the cell to the MS. In the commercial cell displaying larger dead volume the gas is not completely exchanged over the time that oxygen (33 s) is admitted to the cell. The He signal does not reach a steady state value and the same intensity obtained in the novel cell. Clearly, the new cell design makes it possible to 


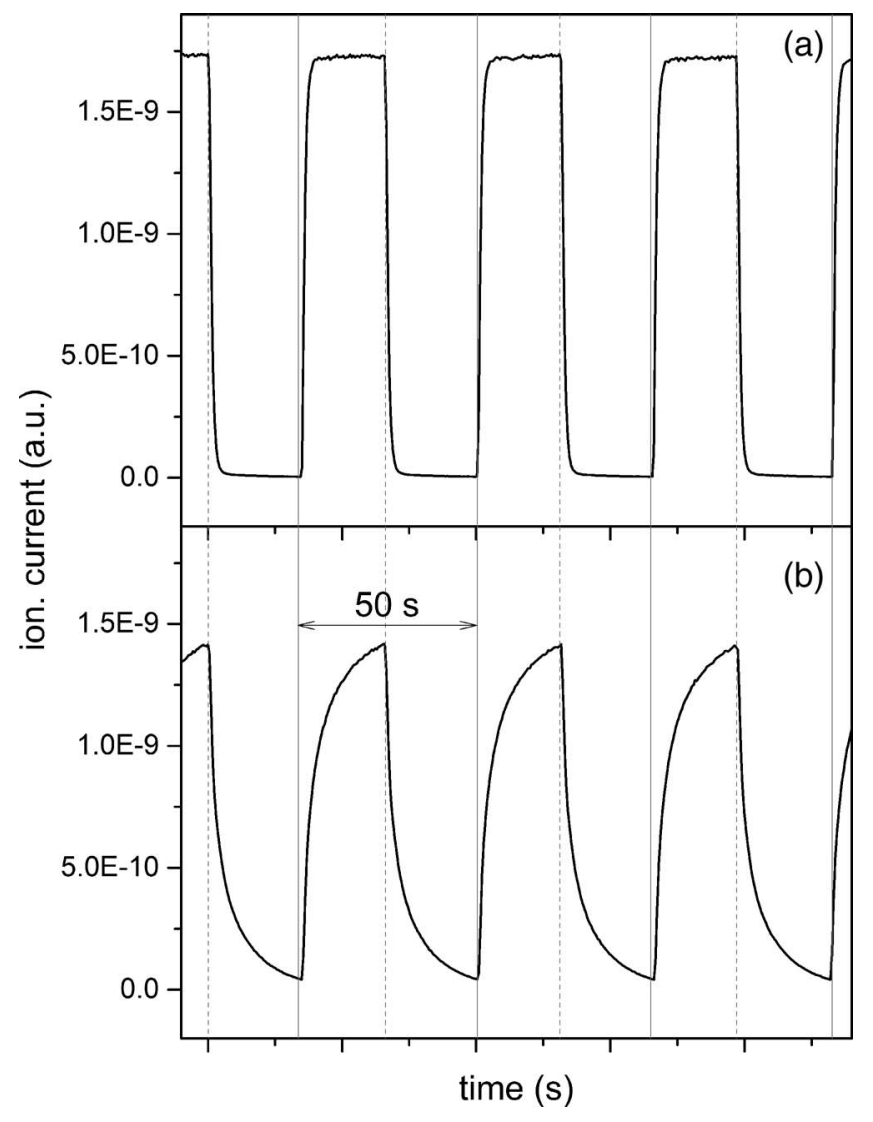

FIG. 3. Temporal variation of the signal of $\mathrm{He}(\mathrm{m} / \mathrm{z}=4)$ during a $2.5 \mathrm{vol} . \%$ $\mathrm{CO} / 2.5 \mathrm{vol} . \% \mathrm{He} / \mathrm{Ar}$ and $2.5 \mathrm{vol} . \% \mathrm{O}_{2} / \mathrm{Ar}$ modulation experiment $(\mathrm{T}=66 \mathrm{~s})$ on $\mathrm{Pt} / \mathrm{Al}_{2} \mathrm{O}_{3}$ at $150^{\circ} \mathrm{C}$ in the new cell (a) and in the commercial cell (b).

achieve faster gas exchange rates because of the reduced dead volume (Figure 1(b)).

\section{B. Characterization of time-resolved XAS through the new cell}

Given the unusual geometry of this XAS-DRIFTS combination compared to existing geometries, the choice of the window material on the cell side where the IR radiation is coupled to the sample is crucial. Conventional IR transparent windows (thickness $0.5 \mathrm{~mm}$ ), i.e., $\mathrm{CaF}_{2}, \mathrm{MgF}_{2}, \mathrm{ZnSe}$, and diamond have been tested. The EXAFS spectra of the $\mathrm{Pt} / \mathrm{Al}_{2} \mathrm{O}_{3}$ catalyst measured around the $\mathrm{Pt}_{3}$-edge are presented in Figure 4 and demonstrate that crystalline materials strongly interfere in the XAS spectra. Diffraction features are visible in the spectra at different points which make EXAFS analysis difficult if not impossible. Although diamond does not provide a completely clean spectrum (inset of Figure 4), C-based windows are clearly suitable for EXAFS. In the following we show the data quality obtained using different window materials also suitable for the combination with DRIFTS. Obviously, the XAS spectra are cleaner and the spectral quality is higher in the case of the graphite window (Figure 4).

The $\mathrm{L}_{3}$-edge probes the empty density of states and the oxidation state of $\mathrm{Pt}^{4}{ }^{4}$ The whiteline of $\mathrm{L}_{3}$-edge XAS spectra is sensitive to anti-bonding states as a consequence of coordination of adsorbates such as $\mathrm{CO}^{45,46}$ Therefore, we have

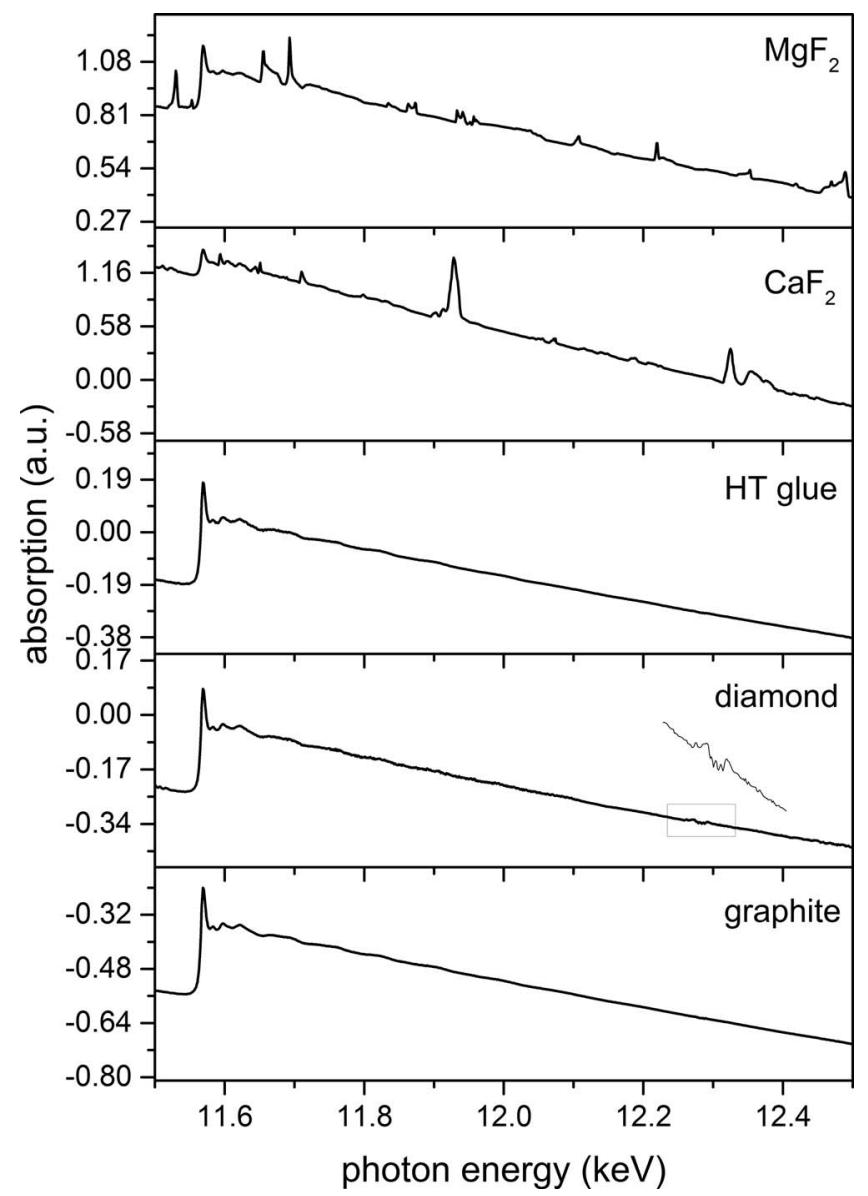

FIG. 4. $\mathrm{Pt} \mathrm{L}_{3}$-edge EXAFS spectra of $\mathrm{Pt} / \mathrm{Al}_{2} \mathrm{O}_{3}$ acquired with different window materials and showing the presence of diffraction patterns due to the crystalline inorganic windows. The inset shows interference from crystalline diamond at high energy $(\sim 12.27 \mathrm{keV})$.

carried out measurements of $\mathrm{CO}$ and $\mathrm{H}_{2}$ adsorption-reaction at $150^{\circ} \mathrm{C}$ to demonstrate the suitability of the novel cell for EXAFS data acquisition and analysis. Furthermore, because of the low cell dead volume the modulation approach was used to demonstrate the high quality of the phase-resolved spectra mirroring the small structural changes (oxidationreduction) of the supported Pt nano-particles.

A typical sequence of raw $\mathrm{Pt}_{3}$-edge quickEXAFS data recorded during a $\mathrm{CO}-\mathrm{O}_{2}$ modulation experiment at $150{ }^{\circ} \mathrm{C}$ on reduced $\mathrm{Pt} / \mathrm{Al}_{2} \mathrm{O}_{3}$ using a diamond window is reported in Figures 5(a) and 5(b). ${ }^{47}$ The raw data consist of a sequence of EXAFS spectra with increasing and decreasing energy because of the continuous oscillation of the $\mathrm{Si}(111)$ crystal monochromator (Figure 5(b)). The synchronously recorded signal of the solenoid switch valve is also displayed; $\mathrm{CO}$ is admitted to the cell when the valve is on, while $\mathrm{O}_{2}$ is introduced when it is off. Figure 5(c) shows the elaborated averaged time-resolved quickEXAFS spectra in the XANES region of the $\mathrm{Pt}_{3}$-edge. A periodic change of the whiteline intensity in response to the periodic stimulation provided by the alternate $\mathrm{CO}$ and $\mathrm{O}_{2}$ pulses $(30 \mathrm{~s})$ is evident. The slight increase (in $\mathrm{O}_{2}$ ) and decrease (in $\mathrm{CO}$ ) of the whiteline intensity demonstrates the expected redox dynamic of the metallic Pt nanoparticles that undergo a partial and reversible 

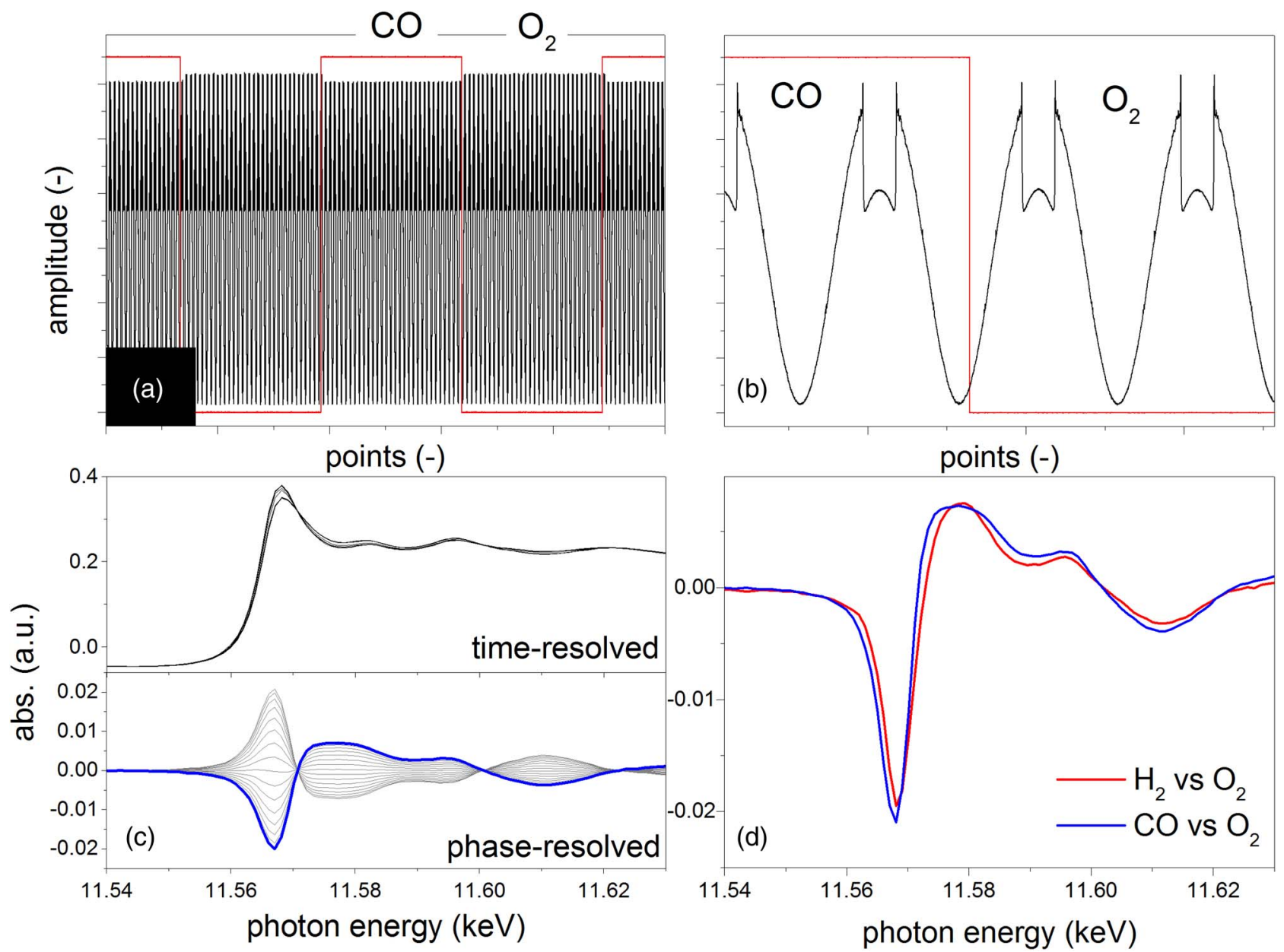

FIG. 5. (a) Raw quickEXAFS data recorded at the $\mathrm{Pt}_{3}$-edge during the 5 vol. $\% \mathrm{CO} / \mathrm{He}-5 \mathrm{vol} . \% \mathrm{O}_{2} / \mathrm{He}$ modulation experiment on $\mathrm{Pt} / \mathrm{Al}_{2} \mathrm{O}_{3}$ at $150{ }^{\circ} \mathrm{C}$ using a diamond window; the red line is the electric signal of the switch valve. (b) Detail of (a) around a $\mathrm{CO}-\mathrm{O}_{2}$ switch. (c) Set of averaged time- and corresponding phase-resolved data recorded at the $\mathrm{Pt}_{3}$-edge. (d) Selected phase-resolved data obtained during the 5 vol. $\% \mathrm{CO} / \mathrm{He}-5$ vol. $\% \mathrm{O}_{2} / \mathrm{He}$ and 5 vol. $\% \mathrm{H}_{2} / \mathrm{He}-5$ vol\% $\mathrm{O}_{2} / \mathrm{He}$ modulation experiments.

re-oxidation in $\mathrm{O}_{2}$ and full reduction in $\mathrm{CO}^{30}$ Thanks to the attenuation of the noise after averaging over 30 consecutive modulation periods, the obtained time-resolved XAS data can be analysed by conventional XAS data fitting, which will deliver the dynamic local structural changes (i.e., type, number and distance of neighbouring atoms). Figure 5(c) also shows the corresponding phase-resolved data. Phase sensitive detection (PSD) is used in MES to extract the spectral components that vary according to and with the same frequency of the external stimulation (i.e., the frequency of $\mathrm{CO}-\mathrm{O}_{2}$ modulation) thus massively increasing the sensitivity of any spectroscopic method to subtle but likely relevant structural changes. Hence, the phase-resolved data of the experiment on $\mathrm{Pt} / \mathrm{Al}_{2} \mathrm{O}_{3}$ clearly contain information only about that portion of $\mathrm{Pt}$ that is stimulated by the $\mathrm{CO}-\mathrm{O}_{2}$ modulation. For example, the difference between the in-phase XANES spectra (corresponding to the one in Figure 5(c) with the maximum intensity at $\sim 11.58 \mathrm{keV}$ ) obtained for the $\mathrm{CO}-\mathrm{O}_{2}$ experiment and that for an equivalent $\mathrm{H}_{2}-\mathrm{O}_{2}$ modulation experiment at $150^{\circ} \mathrm{C}$ is particularly evident in Figure 5(d). Because the phase-resolved spectra are proportional to the difference XAS spectra between the two boundary states of the catalyst under the two different gas atmospheres, i.e., the most reduced and the most oxidized state, and considering that the final state of $\mathrm{Pt}$ in $\mathrm{O}_{2}$ in the two experiments is most likely the same, one can conclude that the difference in the two spectra of Figure 5(d) is due to a change in the shape of the XANES spectra of the fully reduced state of $\mathrm{Pt}$ (i.e., under $\mathrm{CO}$ or $\mathrm{H}_{2}$ stream). Hence, such changes can be understood in terms of Pt-CO and Pt-H species visible by XANES, respectively. ${ }^{45,48}$

Figure 6 shows the averaged time-resolved quick EXAFS spectra recorded in an equivalent experiment when the cell was equipped with a $\mathrm{MgF}_{2}$ window to allow for the synchronous DRIFTS measurement (see Sec. III C and Figure 10(c)). Large diffraction peaks of the crystalline window material are observed in the time-resolved spectra. However, PSD is able to filter these static signals and to provide high-quality phase-resolved XAS data for further evaluation (see, for example, Ref. 30).

The averaged time-resolved $\mathrm{k}^{2}$-weighted quickEXAFS spectra resulting from the $\mathrm{CO}-\mathrm{O}_{2}$ modulation experiment on $\mathrm{Pt} / \mathrm{Al}_{2} \mathrm{O}_{3}$ using the diamond window shown in Figure 7 demonstrate the high data quality that can be achieved with the novel cell in the $\mathrm{k}$ range of $2-13 \AA^{-1}$. Although diamond is more suitable for $\mathrm{X}$-ray absorption spectroscopy than the other IR transparent materials, similar artefacts to those 


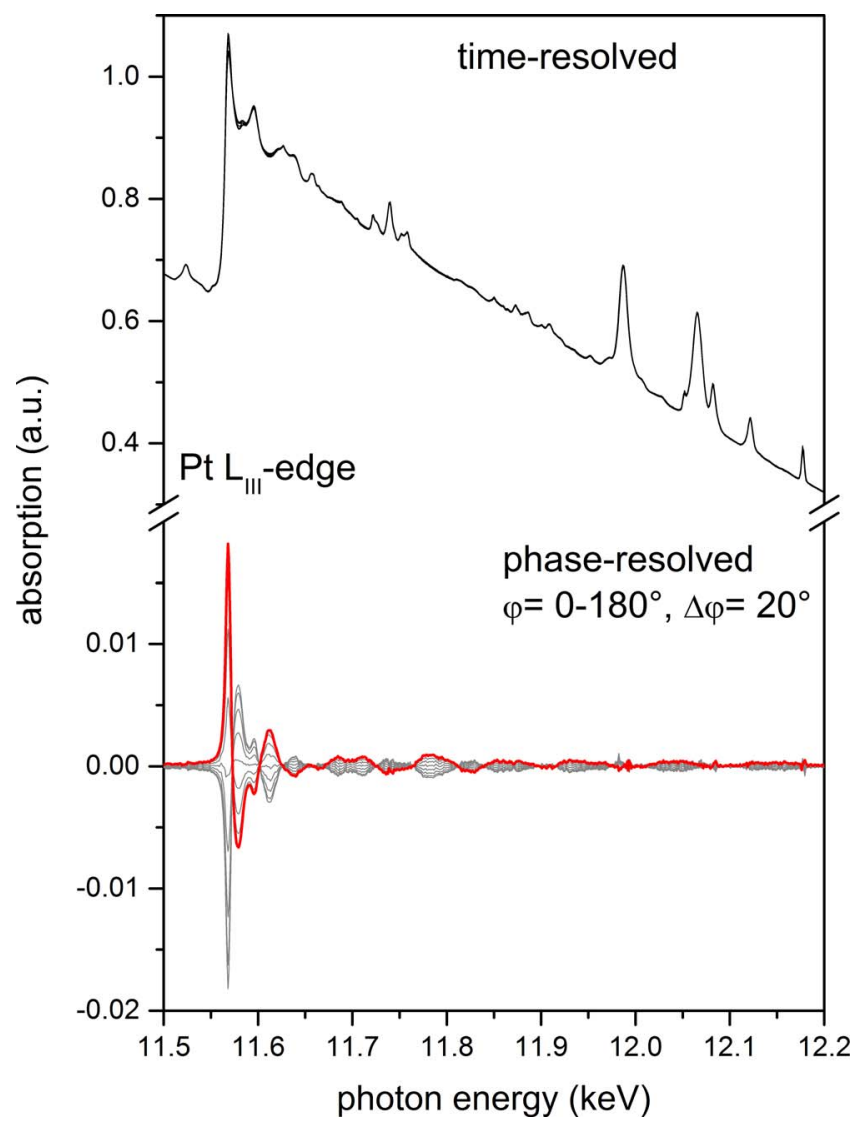

FIG. 6. Time- and selected phase-resolved quickEXAFS data obtained during a synchronous XAS-DRIFTS modulation experiment $(5 \mathrm{vol} . \% \mathrm{CO} / \mathrm{He}-5$ vol. $\% \mathrm{O}_{2} / \mathrm{He}$ ) on $\mathrm{Pt} / \mathrm{Al}_{2} \mathrm{O}_{3}$ at $150{ }^{\circ} \mathrm{C}$ using a $\mathrm{MgF}_{2}$ window. The $\varphi^{\mathrm{PSD}}$ range is indicated.

observed with $\mathrm{MgF}_{2}$ also occur at high energy in the spectrum of the $\mathrm{Pt}_{3}$-edge (inset of Figure 4) that can be largely removed by PSD. In the displayed k-range, the phase-resolved spectra vary between two red and blue boundary spectra without displaying any $\mathrm{k}$ shift. Therefore, the two spectra represent the two boundary structures reflecting the whiteline changes of Figure 5(c) indicating that the Pt nano-particles are partially oxidized in the $\mathrm{O}_{2}$ pulse. ${ }^{30}$ The phase-resolved spectra can be Fourier transformed to better distinguish the variation induced by the modulation experiments on each involved scattering path (i.e., coordination shells surrounding the absorbing atom), as shown in Figure 8(a). The spectra can be compared with the FT spectra obtained at the end of the $\mathrm{CO}$ and $\mathrm{O}_{2}$ pulses corresponding to the most reduced and most oxidized states of the catalyst at the given temperature (Figure 8(b)). The spectral changes induced by the gas phase modulation are clearly small but visible in the high quality time-resolved data. However, PSD is in principle able to provide a deeper view in the red-ox process as only those changes are highlighted, whereas static contributions are removed from the spectra of Figure 8(a). The static contribution corresponds to that portion of the metallic $\mathrm{Pt}$ nano-particles that is not involved in the red-ox process stimulated by the $\mathrm{CO}-\mathrm{O}_{2}$ modulation. The (non-phase shift corrected) FT phase-resolved spectra show that changes are predominantly associated with the Pt-O and Pt-Pt coordi-

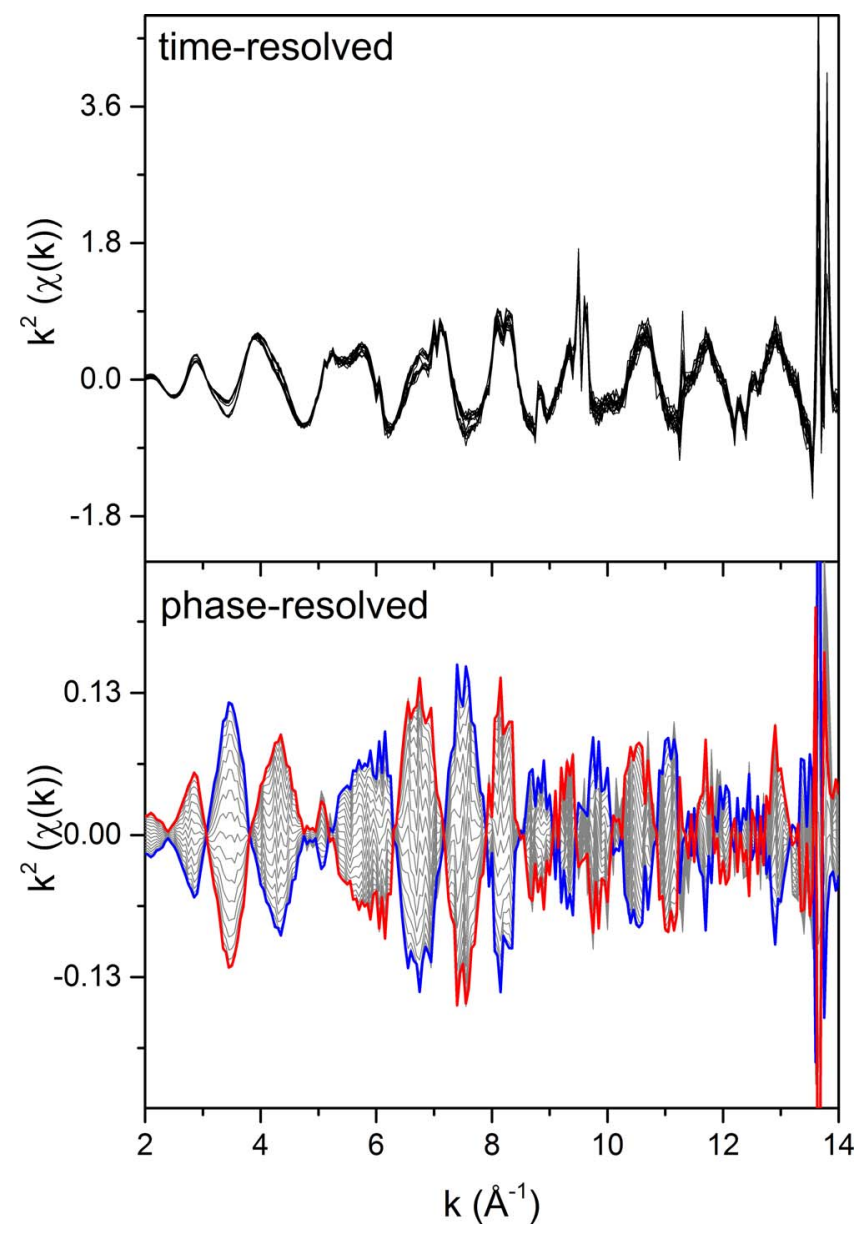

FIG. 7. (a) Time- and (b) phase-resolved $\mathrm{k}^{2}$-spectra collected during a 5 vol. $\% \mathrm{CO} / \mathrm{He}-5$ vol. $\% \mathrm{O}_{2} / \mathrm{He}$ modulation experiment on reduced $\mathrm{Pt} / \mathrm{Al}_{2} \mathrm{O}_{3}$ at $150^{\circ} \mathrm{C}$ using a diamond window. Red and blue spectra are highlighted in order to show the boundaries within which spectral variations occur.

nation shells and present features at 1.22, 1.56, 2.14, 2.51, 2.85 , and $3.19 \AA$. The signals at 1.56 and $2.51 \AA$ are readily assigned to the Pt-O shell of oxidized Pt and the Pt-Pt shell of metallic Pt by comparison with the reference materials (Figure 8(c)), respectively. The signals at 1.22 and $3.19 \AA$ are also attributed to oxidized Pt. The latter is weaker compared to the corresponding feature in the spectrum of $\mathrm{PtO}_{2}$ indicating that the Pt-O layer forming during the $\mathrm{O}_{2}$ pulse is thin and does not provide sufficient scattering of Pt-O-Pt neighbor atoms of the second coordination shell. This would be in agreement with the oxidized platinum surface with close-packed $\mathrm{Pt}$ and $\mathrm{O}$ layers observed on $1 \mathrm{wt} . \%$ $\mathrm{Pt} / \mathrm{Al}_{2} \mathrm{O}_{3}$ using PDF under similar experimental conditions. ${ }^{49}$ The short $\mathrm{O}_{2}$ pulse is not able to completely oxidize the metallic Pt nano-particles. The signal at $2.85 \AA$ is likely a mixed contribution of oxidized and metallic Pt. Additional experiments are currently scheduled in order to confirm the possibility to distinguish the Pt-C scattering path using the modulated excitation approach coupled to time-resolved EXAFS.

In the geometry that we have selected for the combination of the two spectroscopic techniques, the optimal combination can be achieved only with a window composed of both IR and X-ray transparent materials where however the IR transparent material does not disturb the X-rays. Therefore, a hole 


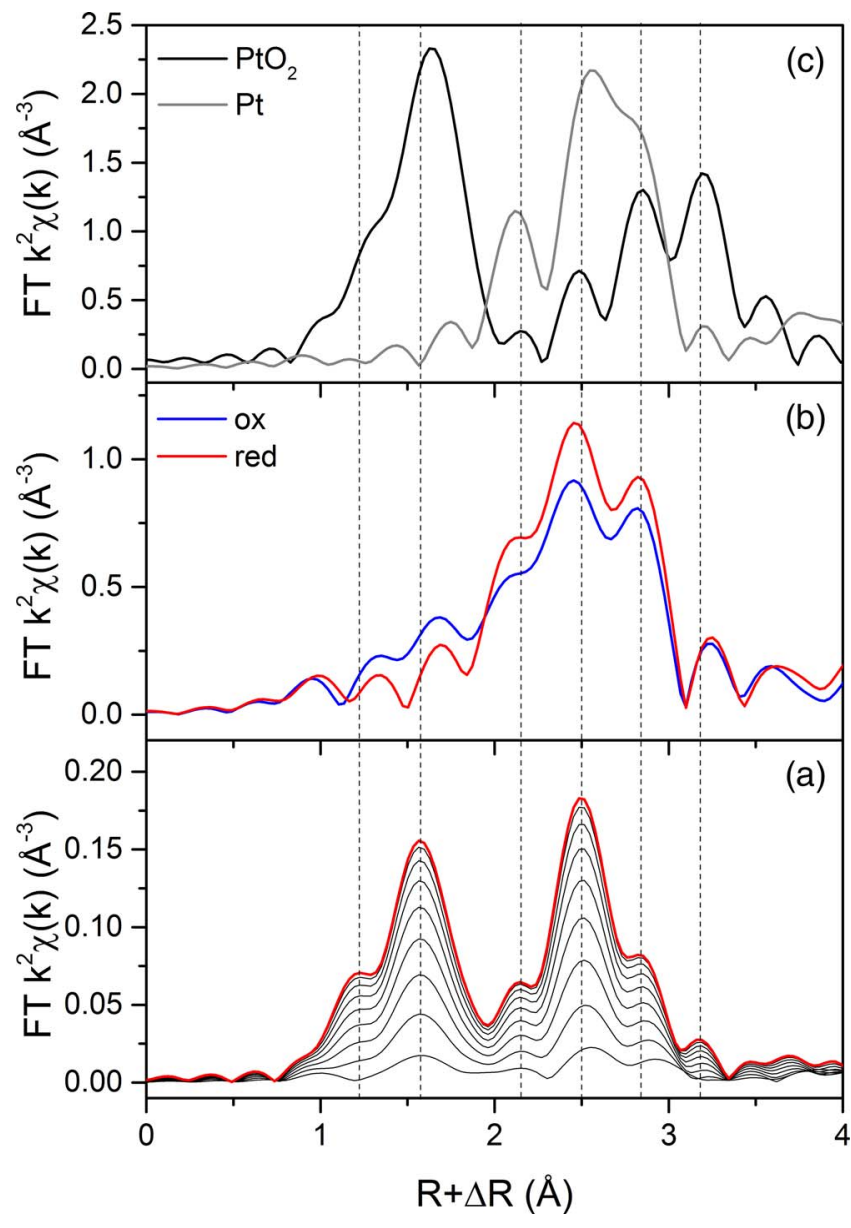

FIG. 8. $\mathrm{k}^{2} \chi(\mathrm{k})$ Fourier transforms (FT) of (a) the phase-resolved spectra $\left(0^{\circ}<\varphi^{\mathrm{PSD}}<80^{\circ}\right)$ obtained in the modulation experiment of Figure 7 , (b) the time-resolved spectra of Figure 7 corresponding to most reduced (red) and most oxidized (blue) states, and (c) the reference materials, $\mathrm{PtO}_{2}$ and $\mathrm{Pt}$ foil.

$(d=0.5 \mathrm{~mm})$ was laser drilled in the middle of the $\mathrm{CaF}_{2}$ window and filled with the high temperature carbon based glue used to prepare the window providing the spectrum displayed in Figure 4. This geometry of the X-ray beam allows to pass $(\sim 0.1 \mathrm{~mm})$ through the $\mathrm{C}$-filled hole and to simultaneously record IR spectra (selected beam size of $8 \mathrm{~mm}$ ). Figure 9(a) shows the $\mathrm{x}$ - and $\mathrm{y}$-position scan operated with the beamline motors at fixed energy of $11.61 \mathrm{keV}$ (i.e., just above the Pt $\mathrm{L}_{3}$-edge). The highest transmission is obtained through the C-filled hole, whereas transmitted energy is very low around it because of the additional absorption by $\mathrm{CaF}_{2}$ and dispersion by X-ray diffraction due to the $\mathrm{CaF}_{2}$ crystal lattice at that energy (Figure 9(b)). The difference between the EXAFS spectrum of the $\mathrm{Pt} / \mathrm{Al}_{2} \mathrm{O}_{3}$ catalyst measured through the $\mathrm{C}$-filled hole and the spectrum measured few microns away in the $\mathrm{CaF}_{2}$ window demonstrates the improved quality of the EXAFS data, which now allows in situ EXAFS with simultaneous IR acquisition of the investigated materials.

\section{Diffuse reflectance infrared spectroscopy}

In this section, it is demonstrated that the novel reactor cell delivers high quality DRIFT spectra. For this pur-
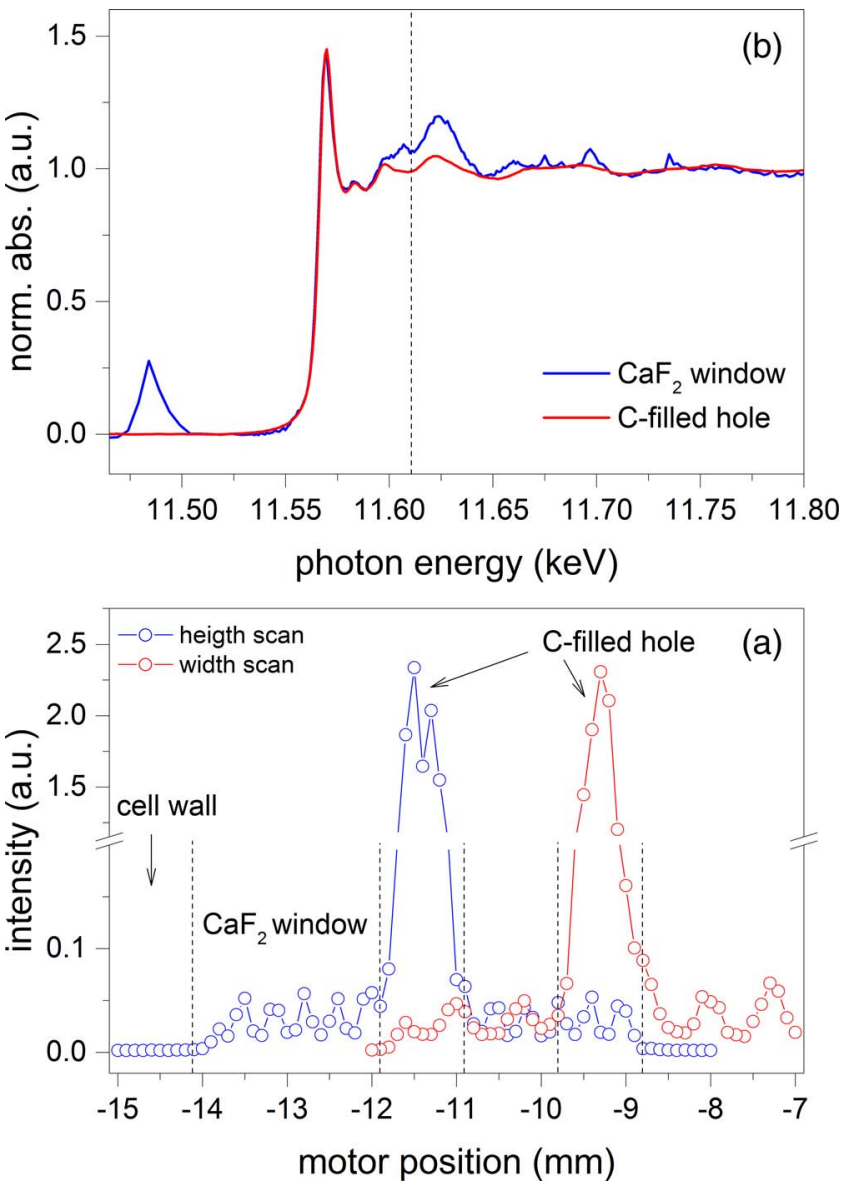

FIG. 9. (a) $\mathrm{X}$ - and $\mathrm{y}$-position scan along a $\mathrm{CaF}_{2}$ window with $\mathrm{C}$-filled hole used to align the $\mathrm{Pt} / \mathrm{Al}_{2} \mathrm{O}_{3}$ catalyst in the $\mathrm{X}$-ray beam. Scans were taken at $11.61 \mathrm{keV}$ incident photon energy. (b) $\mathrm{Pt}_{3}$-edge spectra acquired in the middle of the $\mathrm{C}$-filled hole (red) and in the $\mathrm{CaF}_{2}$ window (blue).

pose, the $\mathrm{Pt} / \mathrm{Al}_{2} \mathrm{O}_{3}$ catalyst was subjected to a $\mathrm{CO}-\mathrm{O}_{2}$ modulation experiment at $150^{\circ} \mathrm{C}$ independent of the EXAFS experiment. From the IR viewpoint, adsorbed CO is easily detectable on solid catalysts containing precious metals because of the strong absorption coefficient of the $\mathrm{C}-\mathrm{O}$ bond and thus represents a suitable surface probe molecule. ${ }^{50}$ Adsorption of $\mathrm{CO}$ on regular Pt surfaces ${ }^{51,52}$ and supported Pt catalysts ${ }^{53,54}$ is well documented in the literature. Observation of adsorbed $\mathrm{CO}$ is used as a fingerprint for the characterization of the novel cell in terms of tracking adsorption on powder materials. For the sake of comparison, the same experiment was repeated using the commercial cell. The main differences between the two cells are the dead volume and the sample fraction that is sampled by the IR radiation. The dead volume of the novel cell is given only by the inner volume of the $1 / 16$ in. stainless steel tubing from the switch valves to the sample and from the sampe to the MS. It is intuitively smaller compared to that of the commercial cell. In the commercial cell, the top section of the sample ( $\sim 5 \mathrm{~mm} \times 5 \mathrm{~mm}$, round sample holder) is probed where the gas comes into contact with the sample. In the novel cell, the IR radiation is coupled in on the side of the catalyst bed $(\sim 5 \mathrm{~mm} \times 5 \mathrm{~mm} \times 2 \mathrm{~mm}$, rectangular sample holder). Additionally, the IR radiation passes through the gas phase that is fed on top of the sample in the commercial cell, 


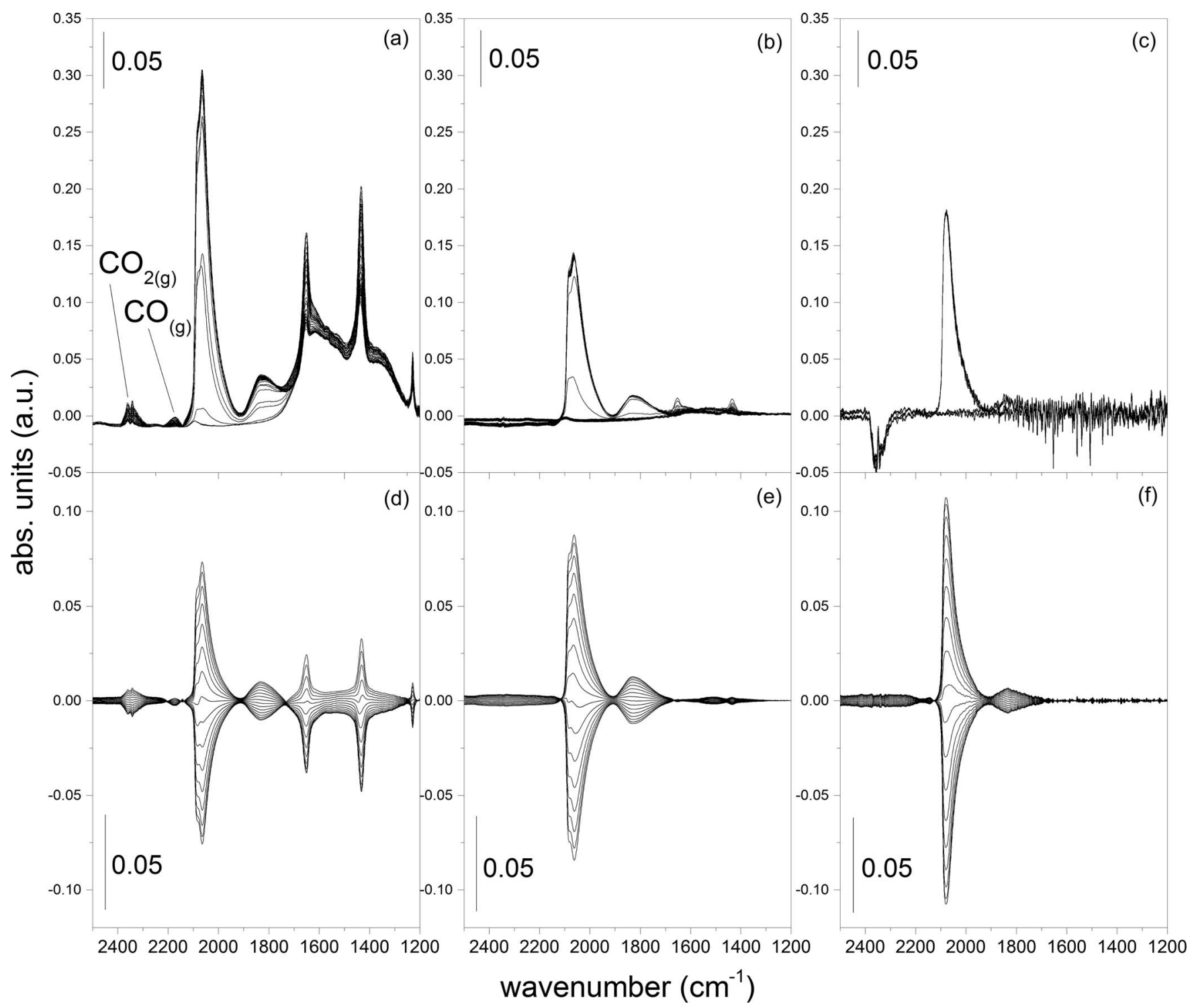

FIG. 10. Time-resolved DRIFTS spectra collected during a modulation experiment 2.5 vol. $\% \mathrm{CO} / \mathrm{Ar}-2.5$ vol. $\% \mathrm{O}_{2} / \mathrm{Ar}$ on reduced $\mathrm{Pt} / \mathrm{Al}_{2} \mathrm{O}_{3}$ at $150{ }^{\circ} \mathrm{C}$ using (a) the commercial cell at lab scale $\left(\mathrm{CaF}_{2}\right.$ window), (b) the novel cell at lab scale $\left(\mathrm{MgF}_{2}\right.$ window), and (c) the novel cell in the combined XAS-DRIFTS measurement $\left(\mathrm{MgF}_{2}\right.$ cell). Spectra (d)-(f) are the corresponding phase-resolved data.

whereas it measures directly the sample in the novel cell. The penetration depth of the IR radiation in the sample in a modified Harrick cell was estimated to $0.2 \mathrm{~mm} .{ }^{18}$ Therefore, in our design a larger section of the sample is probed by the IR radiation compared to the commercial cell because the sample thickness is only $2 \mathrm{~mm}$.

Figure 10(a) shows the DRIFT spectra collected with the commercial cell at $150{ }^{\circ} \mathrm{C}$ using a $\mathrm{CaF}_{2}$ window and the conventional DRIFTS mirror unit mounted in the sample compartment of the spectrometer. We are reporting absorbance spectra rather than the typical Kubelka-Munk spectra in line with previous observations, ${ }^{55}$ though no quantitative adsorbate determination was attempted here. The signals at 2070 and $1830 \mathrm{~cm}^{-1}$ correspond to adsorbed $\mathrm{CO}$ on the finely dispersed $\mathrm{Pt}$ nano-particles in linear $\left(\mathrm{CO}_{\mathrm{L}}\right.$, Pt-CO) and bridge $\left(\mathrm{CO}_{\mathrm{B}}, \mathrm{Pt}_{3}-\mathrm{CO}\right.$, and $\left.\mathrm{Pt}_{2}-\mathrm{CO}\right)$ coordination, respectively. ${ }^{56} \mathrm{Ad}-$ ditional signals at 1652 and $1434 \mathrm{~cm}^{-1}$ are assigned to bicarbonate species coordinated to $\gamma-\mathrm{Al}_{2} \mathrm{O}_{3} \cdot{ }^{57,58}$ The same exper- iment performed by exchanging only the cell to the novel cell (flat $\mathrm{MgF}_{2}$ window, same mirror unit) provides the spectra of Figure 10(b). Beside intensity variations, the same $\mathrm{CO}$ species and intensified signals at 1650,1435 , and $1229 \mathrm{~cm}^{-1}$ characteristic of bicarbonate species ${ }^{57}$ are observed. The shape of the signals of adsorbed $\mathrm{CO}$ on $\mathrm{Pt}$ is identical indicating that the experiment was able to probe the same portion of catalyst. A major difference is observed in the case of the signals of bicarbonate species, which are more intense in the experiment with the commercial cell. We tentatively attribute the intensity difference between the two experiments to the temperature difference of the section of sample that is probed by the IR radiation. In the commercial cell, the top section of the catalyst is likely colder than the core of the sample, where the IR radiation does not penetrate. On the contrary, in the novel cell the side of the sample in contact with the IR transparent window is approximately at the temperature of the sample core. Bicarbonate species observed in Figure 10(a) are stable 


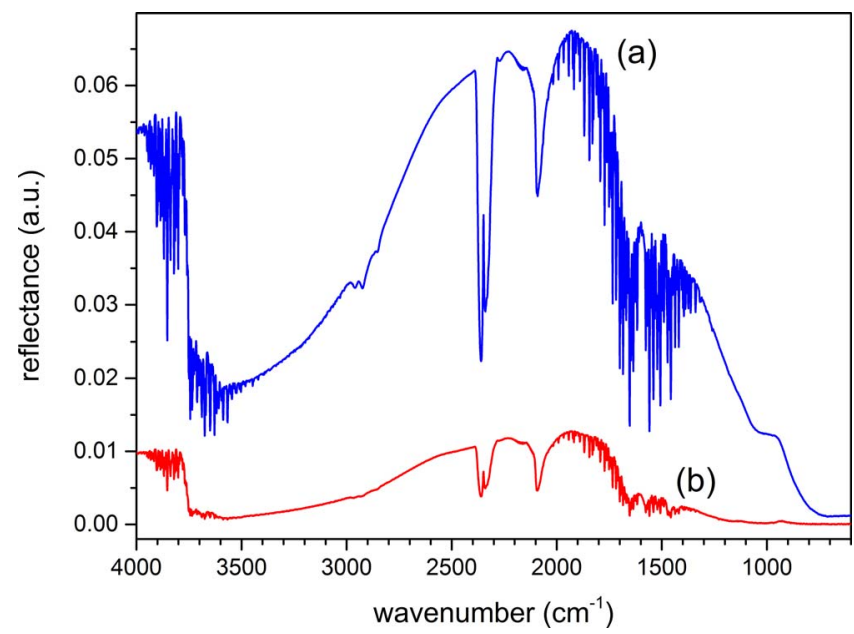

FIG. 11. (a) Single channel DRIFT spectrum of reduced $\mathrm{Pt} / \mathrm{Al}_{2} \mathrm{O}_{3}$ obtained after maximization of light throughput using the novel cell and the Praying Mantis mirror set. (b) Single channel DRIFT spectrum of reduced $\mathrm{Pt} / \mathrm{Al}_{2} \mathrm{O}_{3}$ obtained after maximization of $\mathrm{CO}_{\mathrm{L}}$ signal.

at low temperature ${ }^{59}$ which could confirm our interpretation based on the different sample temperature.

It should be noted that in these experiments no gas phase $\mathrm{CO}_{2}$ and $\mathrm{CO}$ signals are observed in the novel cell although the same $\mathrm{CO}$ concentration was employed because the only visible $\mathrm{CO}$ by the IR radiation is that present within the interparticle interstices and the pores of the sample. These signals are well visible with the commercial cell since the IR radiation passes through the gas phase (Figure 10(a) and Figure 1(b)). As a consequence of the cell design, the experiment with the new cell is less sensitive to gas phase products, e.g., the $\mathrm{CO}_{2}$ product of $\mathrm{CO}$ oxidation evolving in correspondence of the $\mathrm{CO} \rightarrow \mathrm{O}_{2}$ and $\mathrm{O}_{2} \rightarrow \mathrm{CO}$ switches (Figure 10(a)).

The DRIFT spectra collected for the same experiment at $150{ }^{\circ} \mathrm{C}$ in the combined XAS-IR experiment with the dedicated DRIFTS mirror unit and using the $\mathrm{MgF}_{2}$ window are shown in Figure 10(c). The corresponding EXAFS spectra are shown in Figure 6. Signals of $\mathrm{CO}_{\mathrm{L}}$ and $\mathrm{CO}_{\mathrm{B}}$ on $\mathrm{Pt} / \mathrm{Al}_{2} \mathrm{O}_{3}$ at 2070 and $1830 \mathrm{~cm}^{-1}$ are clearly detected, demonstrating the successfull combination of the two spectroscopic techniques in a single experiment. However, some significant difference can be observed when comparing DRIFT spectra of the same experiment performed in the spectrometer (Figure 10(b)) or at the beamline (Figure 10(c)), e.g., the signals of carbonate species are hardly observed even in the demodulated spectra (Figure 10(f)). This difference is attributed to the difficulty to correctly align the cell into the mirror unit when the cell and the mirror unit are independent, i.e., during the combined XAS-DRIFTS experiment. This issue is likely the consequence of the large contribution of specular reflection that needs to be taken into account when a flat IR window is used in diffuse reflectance measurements. Figure 11 shows two DRIFT single channel spectra measured while optimizing the alignment of the new cell in the Praying Mantis mirror set. Adsorbed $\mathrm{CO}$ is exploited as a probe of the catalyst surface because it is a strong IR absorber. Therefore, alignment is made by maximizing the contribution from adsorbed $\mathrm{CO}$ while $\mathrm{CO}$ is flowing on the reduced sample at am- bient temperature. The two spectra correspond to the single channel spectrum collected when optimizing the count rate on the $\mathrm{HgCdTe}$ detector (Figure 11(a)) and the single channel spectrum acquired when optimizing the relative ratio of the $\mathrm{CO}_{\mathrm{L}}$ signal with respect to zero reflectance (Figure 11(b)). The intensity of the $\mathrm{CO}_{\mathrm{L}}$ signal is less than one third of the overall spectrum intensity at $\sim 2070 \mathrm{~cm}^{-1}$ when optimizing the count rate, whereas it is more than $50 \%$ when alignment is performed by optimizing the $\mathrm{CO}_{\mathrm{L}}$ intensity. Similarly, the continuum extending from 3600 to $2500 \mathrm{~cm}^{-1}$ representing hydrogen bonded Al-OH groups ${ }^{60}$ becomes more evident in the latter case indicating that the overall sensitivity of the system is increased towards the sample. The contribution of specular reflection to the overall count rate in the single channel spectrum of Figure 11(a) is larger than in Figure 11(b) and decreases the sensitivity to the surface and our capability to correctly align the cell with respect to the parabolic mirrors of the Praying Mantis. This issue will be fixed in the next generation sample positioning and mirror units.

The phase-resolved spectra obtained from the measurements of Figures 10(a)-10(c) exhibit only signals of those species that are responding actively to the external stimulus of $\mathrm{CO}$ and $\mathrm{O}_{2}$ concentration variation. ${ }^{30}$ Beside highlighting variations associated with gaseous $\mathrm{CO}_{2}$ and $\mathrm{CO}$ (Figure $10(d))$ they also offer the possibility to better distinguish between two distinct $\mathrm{CO}_{\mathrm{L}}$ species at 2084 and $2067 \mathrm{~cm}^{-1}$ corresponding to adsorption on different Pt faces and/or defects, ${ }^{39}$ and their kinetics, whose discussion is however out of the scope of this work.

\section{CONCLUSIONS}

In this work we have developed a novel spectroscopic cell and setup for combined and synchronous in situ XAS and DRIFTS measurements of powder materials. A common design for a XAS cell has been adapted to perform simultaneously DRIFTS measurements by focusing through a suitable optical window transparent to both radiations (IR and X-ray). We have shown that EXAFS spectra may be affected by the crystallinity of the material chosen for this window (diamond, $\mathrm{MgF}_{2}$ or $\mathrm{CaF}_{2}$ ). However, the contribution of interfering signals can be successfully removed in the modulated excitation experiments followed by PSD transformation of the XAS spectra in the phase domain. Additionally, a C-filled hole drilled in $\mathrm{CaF}_{2}$ window specifically designed for combined XAS-DRIFTS has been demonstrated allowing measuring high quality XAS spectra without further interference from the IR transparent material. The novel cell with the flat IR transparent window in contact with the sample provides also high quality DRIFTS spectra that are comparable with those obtained with the widely used commercial cell compared in this work.

We anticipate that the cell presented here is versatile enough to be used with a number of other in situ and operando spectroscopic and diffraction methods. Hence, the novel cell would allow gathering structural information using a number of analytical methods without changing each time the cell design and cell environment. 


\section{ACKNOWLEDGMENTS}

The financial support from the Competence Centre for Materials Science and Technology (CCMX) and the Swiss National Science Foundation (SNF) under Project Nos. 66 and 200021-138068 is highly appreciated. We are thankful to H. Altorfer (Empa) for drawing the cell and constructing the whole cell environment, to R. Brönnimann (Empa) for providing the specimen of the drilled $\mathrm{CaF}_{2}$ window, to the mechanical workshop of Empa for manufacturing the cell, to B. Meyer and M. Huber for designing the movable IR spectrometer stage, and the mechanical workshop of PSI for manufacturing it. The support from Bruker Optics GmbH (Fällanden, Switzerland) is also greatfully acknowledged.

${ }^{1}$ S. J. Tinnemans, J. G. Mesu, K. Kervinen, T. Visser, T. A. Nijhuis, A. M. Beale, D. E. Keller, A. M. J. vanderEerden, and B. M. Weckhuysen, Catal. Today 113, 3 (2006).

${ }^{2}$ A. Brückner, Chem. Commun. 1761 (2005).

${ }^{3}$ M. O. Guerrero-Perez and M. A. Banares, Catal. Today 113, 48 (2006).

${ }^{4}$ F. C. Meunier, Chem. Soc. Rev. 39, 4602 (2010).

${ }^{5}$ J. G. Mesu, A. M. J. vanderEerden, F. M. F. deGroot, and B. M. Weckhuysen, J. Phys. Chem. B 109, 4042 (2005).

${ }^{6}$ D. C. Koningsberger and R. Prins, $X$-Ray Absorption. Principles, Applications, Techniques of EXAFS, SEXAFS and XANES (John Wiley \& Sons, 1987).

${ }^{7}$ S. Bordiga, E. Groppo, G. Agostini, J. A. vanBokhoven, and C. Lamberti, Chem. Rev. 113, 1736 (2013).

${ }^{8}$ A. Zecchina, D. Scarano, S. Bordiga, G. Spoto, and C. Lamberti, Adv. Catal. 46, 265 (2001).

${ }^{9}$ J. Ryczkowski, Catal. Today 68, 263 (2001).

${ }^{10}$ N. Y. Topsoe, Catal. Today 113, 58 (2006).

${ }^{11}$ T. Armaroli, Oil Gas Sci. Technol. 59, 215 (2004).

${ }^{12}$ P. R. Griffiths and J. A. deHaseth, Fourier Transform Infrared Spectrometry (John Wiley \& Sons, Hoboken, New Jersey, 2007).

${ }^{13}$ M. A. Newton and W. vanBeek, Chem. Soc. Rev. 39, 4845 (2010).

${ }^{14}$ M. A. Newton and M. Fernandez-Garcia, in In-situ Characterization of Heterogeneous Catalysts, edited by P. J. Chupas, J. Hanson, and J. A. Rodriguez (Wiley, 2013).

${ }^{15}$ M. A. Newton, Top. Catal. 52, 1410 (2009).

${ }^{16}$ M. Cavers, J. M. Davidson, I. R. Harkness, L. V. C. Rees, and G. S. McDougall, J. Catal. 188, 426 (1999).

${ }^{17}$ M. A. Newton, B. Jyoti, A. J. Dent, S. G. Fiddy, and J. Evans, Chem. Commun. 2382 (2004).

${ }^{18}$ C. Mondelli, V. DalSanto, A. Trovarelli, M. Boaro, A. Fusi, R. Psaro, and S. Recchia, Catal. Today 113, 81 (2006).

${ }^{19}$ M. A. Newton, M. DiMichiel, A. Kubacka, and M. Fernandez-Garcia, J. Am. Chem. Soc. 132, 4540 (2010).

${ }^{20}$ F. C. Meunier, A. Goguet, S. Shekhtman, D. Rooney, and H. Daly, Appl. Catal., A 340, 196 (2008).

${ }^{21}$ F. C. Meunier, D. Reida, A. Goguet, S. Shekhtman, C. Hardacre, R. Burch, W. Deng, and M. Flytzani-Stephanopoulos, J. Catal. 247, 277 (2007).

${ }^{22}$ N. S. Marinkovic, S. Nebojsa, Q. Wang, and A. I. Frenkel, J. Synchrotron Radiat. 18, 447 (2011).

${ }^{23} \mathrm{H}$. Li, M. Rivallan, F. Thibault-Starzyk, A. Travert, and F. C. Meunier, Phys. Chem. Chem. Phys. 15, 7321 (2013).

${ }^{24}$ K. A. Beyer, H. Zhao, O. J. Borkiewicz, M. A. Newton, P. Chupas, and K. W. Chapman, J. Appl. Crystallogr. 47, 95 (2014).

${ }^{25}$ A. Marcelli, P. Innocenzi, M. A. Newton, G. Rau, U. Schade, and W. Xu, J. Synchrotron Radiat. 19, 892 (2012).

${ }^{26}$ D. Baurecht and U. P. Fringeli, Rev. Sci. Instrum. 72, 3782 (2001).

${ }^{27}$ T. Bürgi, J. Catal. 229, 55 (2005).

${ }^{28}$ C. F. J. König, T. J. Schildhauer, and M. Nachtegaal, J. Catal. 305, 92 (2013).
${ }^{29}$ C. F. J. König, J. A. vanBokhoven, T. J. Schildhauer, and M. Nachtegaal, J. Phys. Chem. C 116, 19857 (2012).

${ }^{30}$ D. Ferri, M. A. Newton, and M. Nachtegaal, Top. Catal. 54, 1070 (2011).

${ }^{31}$ D. Ferri, S. K. Matam, R. Wirz, A. Eyssler, O. Korsak, P. Hug, A. Weidenkaff, and M. A. Newton, Phys. Chem. Chem. Phys. 12, 5634 (2010).

${ }^{32}$ A. Eyssler, E. Kleymenov, A. Kupferschmid, M. Nachtegaal, M. SanthoshKumar, P. Hug, A. Weidenkaff, and D. Ferri, J. Phys. Chem. C 115, 1231 (2011).

${ }^{33}$ R. Caliandro, D. Chernyshov, H. Emerich, M. Milanesio, L. Palin, A. Urakawa, W. vanBeek, and D. Viterbo, J. Appl. Crystallogr. 45, 458 (2012).

${ }^{34}$ D. Chernyshov, W. vanBeek, H. Emerich, M. Milanesio, A. Urakawa, D. Viterbo, L. Palin, and R. Caliandro, Acta Crystallogr. A 67, 327 (2011).

${ }^{35}$ W. vanBeek, H. Emerich, A. Urakawa, L. Palin, M. Milanesio, R. Caliandro, D. Viterbo, and D. Chernyshov, J. Appl. Crystallogr. 45, 738 (2012).

${ }^{36}$ D. Ferri, M. A. Newton, M. DiMichiel, S. Yoon, G. L. Chiarello, V. Marchionni, S. K. Matam, A. Weideklaff, F. Wen, and J. Gieshoff, Phys. Chem. Chem. Phys. 15, 8629 (2013).

${ }^{37}$ D. Ferri, M. A. Newton, M. DiMichiel, G. L. Chiarello, S. Yoon, Y. Lu, and J. Andrieux, "Revealing the Dynamic Structure of Complex Solid Catalysts Using Modulated Excitation X-ray Diffraction," Angew. Chem., Int. Ed. (in press).

${ }^{38}$ Y. Lu, S. Keav, V. Marchionni, G. L. Chiarello, A. Pappacena, M. DiMichiel, M. A. Newton, A. Weidenkaff, and D. Ferri, "Ageing induced improvement of methane oxidation activity of $\mathrm{Pd} / \mathrm{YFeO}_{3}$," Catal. Sci. Technol. (in press).

${ }^{39}$ S. K. Matam, E. V. Kondratenko, M. H. Aguirre, P. Hug, D. Rentsch, A. Winkler, A. Weidenkaff, and D. Ferri, Appl. Catal., B 129, 214 (2013).

${ }^{40}$ P. M. Abdala, O. V. Safonova, G. Wiker, W. vanBeek, H. Emerich, J. A. vanBokhoven, J. Sá, J. Szlachetko, and M. Nachtegaal, Chimia 66, 699 (2012).

${ }^{41}$ M. M. Schubert, T. P. Häring, G. Bräth, H. A. Gasteiger, and R. J. Behm, Appl. Spectrosc. 55, 1537 (2001).

${ }^{42}$ V. DalSanto, C. Dossi, A. Fusi, R. Psaro, C. Mondelli, and S. Recchia, Talanta 66, 674 (2005).

${ }^{43}$ A. Urakawa, N. Maeda, and A. Baiker, Angew. Chem., Int. Ed. 120, 9396 (2008).

${ }^{44}$ M. K. Oudenhuijzen, J. A. vanBokhoven, J. T. Miller, D. E. Ramaker, and D. C. Koningsberger, J. Am. Chem. Soc. 127, 1530 (2005).

${ }^{45}$ D. E. Ramaker and D. C. Koningsberger, Phys. Chem. Chem. Phys. 12, 5514 (2010).

${ }^{46}$ O. V. Safonova, M. Tromp, J. A. vanBokhoven, F. M. F. deGroot, J. Evans, and P. Glatzel, J. Phys. Chem. B 110, 16162 (2006).

${ }^{47}$ J. D. Grunwaldt, M. Beier, B. Kimmerle, A. Baiker, M. Nachtegaal, B. Griesbock, D. Lützenkirchen-Hecht, J. Stötzel, and R. Frahm, Phys. Chem. Chem. Phys. 11, 8779 (2009).

${ }^{48}$ J. Singh, E. M. C. Alayon, M. Tromp, O. V. Safonova, P. Glatzel, M. Nachtegaal, R. Frahm, and J. A. vanBokhoven, Angew. Chem., Int. Ed. 47, 9260 (2008).

${ }^{49}$ M. A. Newton, K. W. Chapman, D. Thompsett, and P. J. Chupas, J. Am. Chem. Soc. 134, 5036 (2012).

${ }^{50}$ K. I. Hadjiivanov and G. N. Vayssilov, Adv. Catal. 47, 307 (2002).

${ }^{51}$ B. E. Hayden and A. M. Bradshaw, Surf. Sci. 125, 787 (1983).

${ }^{52}$ P. Hollins, Surf. Sci. Rep. 16, 51 (1992).

${ }^{53}$ D. M. Haaland, Surf. Sci. 185, 1 (1987).

${ }^{54}$ T. Chafik, O. Dulaurent, J. L. Gass, and D. Bianchi, J. Catal. 179, 503 (1998).

${ }^{55}$ J. Sirita, S. Phanichphant, and F. C. Meunier, Anal. Chem. 79, 3912 (2007).

${ }^{56}$ M. Primet, J. M. Basset, M. V. Mathieu, and M. Prettre, J. Catal. 29, 213 (1973).

${ }^{57}$ K. Föttinger, R. Schlögl, and G. Rupprechter, Chem. Commun. 320 (2008).

${ }^{58}$ G. Busca and V. Lorenzelli, Mater. Chem. 7, 89 (1982).

${ }^{59}$ A. Iordan, M. I. Zaki, and C. Kappenstein, Phys. Chem. Chem. Phys. 6, 2502 (2004)

${ }^{60}$ C. Morterra and G. Magnacca, Catal. Today 27, 497 (1996). 